\title{
TRAINER PENGENDALI MOTOR DC BERBASIS MIKROKONTROLER ARDUINO DALAM PEMBELAJARAN INTERFACE DAN PERIPHERAL
}

\author{
Suharijanto ${ }^{1)}$ \\ ${ }^{1)}$ Dosen Prodi Teknik Elektro Fakultas Teknik Universitas Islam Lamongan \\ Email : Suharijanto2014@gmail.com
}

\begin{abstract}
Abstrak
Penelitian ini bertujuan untuk membuat trainer atau alat peraga pengendali motor DC berbasis mikronkontroler Arduino Atmega328. Trainer atau alat peraga merupakan alat pembelajaran yang dapat diamati melalui panca indra dan sebagai pembantu dalam proses belajar mengajar agar lebih efektif. Dan ini dilakukan untuk membantu mahasiswa dalam mendalami mata kuliah interface dan peripheral yang diajarkan di Prodi Teknik Elektro UNISLA. Ada tiga tahapan dalam merancang bangun pengendali motor DC ini, yaitu tahapan perencanaan, tahapan pembuatan dan tahapan uji coba. Pada tahapan perencanaan ini, kita merencanakan apa yang akan kita buat, sederhananya, kita mau membuat pengendali motor DC yang seperti apa? berguna untuk apa? Hal yang perlu ditentukan dalam tahap ini: jenis motor DC yang digunakan, arah putar motor dan metode pengontrolan yaitu bagaimana putaran motor dikontrol dan digerakkan, mikroprosesor yanga digunakan, dan blok diagram sistem. Tahapan pembuatan, dimana ada dua perkerjaan yang harus dilakukan dalam tahap ini, yaitu pembuatan mekanik, elektronik, dan programming. Tahapan terakhir adalah uji coba, yaitu setelah kita mendownload program ke mikrokontroler berarti kita siap melakukan tahapan terakhir dalam membuat pengontrol motor DC, yaitu uji coba. Dalam tahapan ini mulai di uji arah putaran motor dengan berbagai versi sesuai program. Hasil yang diperoleh dari penelitian ini berupa alat peraga pengendali motor DC karena dalam suatu sistem periferal antarmuka terdapat alat berupa perangkat keras dengan perangkat lunak sebagai media interaktifnya.
\end{abstract}

Kata kunci : Trainer, Motor DC, Mikrokontroler Arduino

\begin{abstract}
This study aims to create a trainer or prop of DC motor controller based on Arduino Atmega328 microncontroller. Trainer is a learning tool that can be observed through the five senses and as a helper in the process of teaching and learning to be more effective. And this is done to assist students in deepening the interface and peripheral courses taught in Prodi Electrical Engineering UNISLA. There are three stages in designing the build of this DC motor controller, namely the stages of planning, stages of making and testing stages. At this stage of planning, we plan what we will make, simply, we want to make what kind of DC motor controller? Useful for what? Things that need to be determined in this stage: the type of DC motor used, the direction of motor rotation and the control method is how the motor rotation is controlled and driven, the microprocessor used, and the system block diagram. Stages of manufacture, where there are two jobs that must be done in this stage, namely the manufacture of mechanics, electronics, and programming. The last stage is the test, that is after we download the program to the microcontroller means we are ready to perform the last stage in making DC motor controller, that is test. In this stage start in the test direction of motor rotation with different versions according to the program.

The results obtained from this research in the form of props DC motor control because in a peripheral system interface there is a tool in the form of hardware with software as an interactive media.
\end{abstract}

Keywords: Trainer, DC Motor, Arduino Microcontroller 


\section{PENDAHULUAN}

Pada zaman sekarang ini, perkembangan teknologi elektronika berkembang begitu cepat, persaingan di bidang elektronika jelas terlihat dengan memperkenalkan teknologi - teknologi digital yang di miliki setiap perusahaan elektronika di dunia. Di balik semua teknologi elektronika yang berkembang sekarang ini ada orang orang yang bekerja keras untuk mewujudkan dan menciptakan teknologi tersebut.

Sumber daya manusia merupakan faktor utama dalam perkembangan teknologi elektronika. Karena tanpa sumber daya manusia yang berkualitas di bidang elektro, perkembangan elektronika tak akan berjalan dan tak akan seperti sekarang ini.

Menciptakan sumber daya manusia yang berkualitas merupakan misi dari setiap universitas di dunia, metode dan kurikulum yang tepat harus di laksanakan untuk mencapai misi tersebut.

Untuk model pendidikan di teknik elektro Universitas Islam Lamongan merupakan gabungan dari proses perkuliahan materi (menerima materi/teori) dan perkuliahan praktikum, karena, pada dasarnya lulusan teknik elektro dituntut untuk memiliki keterampilan yang nantinya bisa diterapkan di dunia pekerjaan. Untuk perkuliahan praktikum memerlukan alat peraga yang menunjang dan membantu para mahasiswa dan mahasiswi untuk menyelesaikan setiap persoalan dalam penerapan teori/materi yang telah diterima.

Sering tidak tersedianya alat peraga, mempersulit mahasiswa dan mahasiswi teknik elektro untuk menerapkan materi/teori yang telah di dapat. Dan mereka lebih sulit mengerti apabila penyampaian hanya di lakukan menggunakan simulasi software dan tidak melihat dan merancang langsung rangkaian elektronika dalam mendalami materi kuliah tersebut.

Untuk dapat melakukan perkuliahan sebagaimana mestinya, penulis mencoba melakukan penelitian dengan membuat alat peraga pengontrol motor DC menggunakan mikrokontroler arduino sebagai salah satu contoh pembelajaran mata kuliah interface dan peripheral.

\section{METODE PENELITIAN Rancangan Penelitian}

Dalam penelitian ini akan dibuat trainer atau alat peraga pengendali motor DC berbasis mikronkontroler Arduino Atmega328.

Secara garis besar, tahapan pembuatan trainer atau alat peraga dapat dilihat pada gambar berikut:

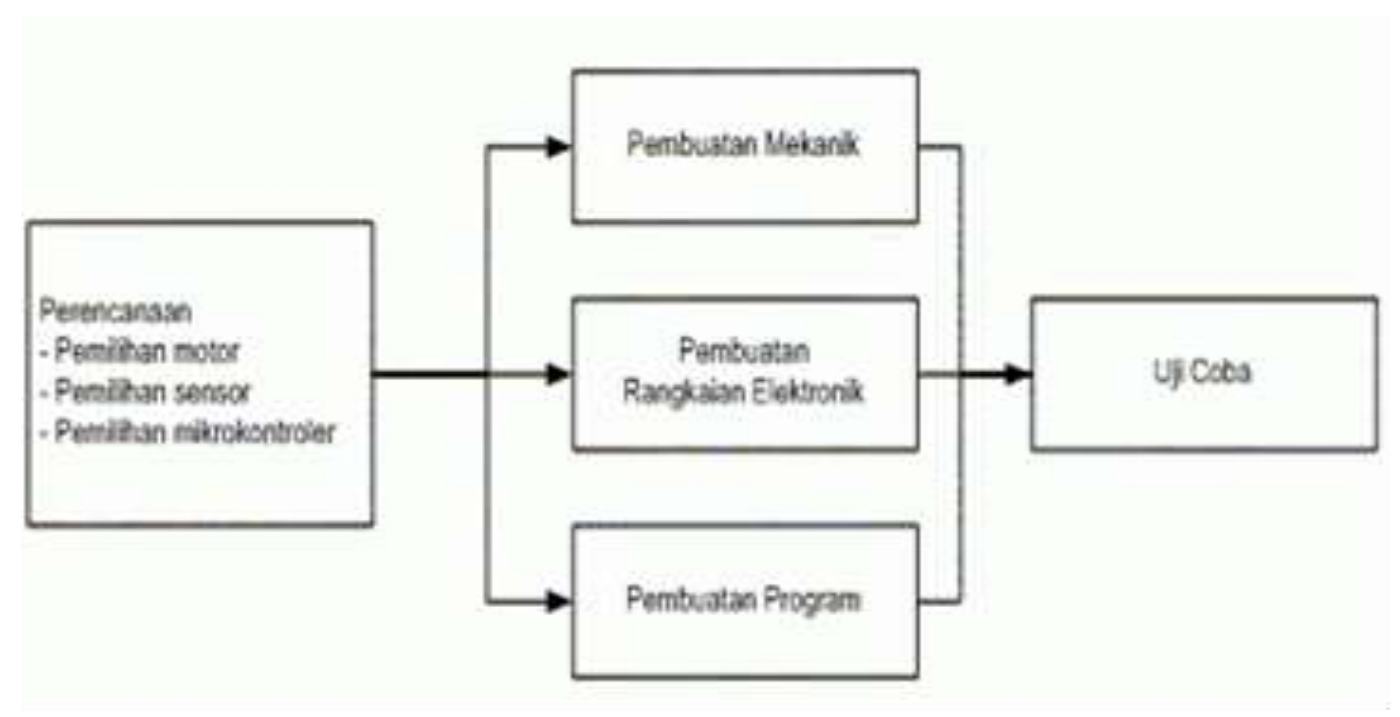

Gambar 1. Blok Diagram Pembuatan

Ada tiga tahapan pembuatan trainer atau alat peraga, yaitu:

1. Perencanaan, meliputi: pemilihan hardware dan design. 
2. Pembuatan, meliputi pembuatan mekanik, elektonik, dan program.

3. Uji coba.

Suhariyanto / Trainer Pengendali Motor Dc Berbasis Mikrokontroler Arduino Dalam Pembelajaran Interface Dan Peripheral/JT,Vol 9 No.1, Maret 2017, pp $23-28$

\section{Tahap perencanan}

Dalam tahap ini, kita merencanakan apa yang akan kita buat, sederhananya, kita mau membuat trainer yang seperti apa? berguna untuk apa? Hal yang perlu ditentukan dalam tahap ini:

- Mekanisme, bagaimana sistem mekanik agar bisa berputar.

- Metode pengontrolan, yaitu bagaimana motor dapat dikontrol dan digerakkan serta blok diagram sistem.

\section{Tahap pembuatan}

Ada tiga perkerjaan yang harus dilakukan dalam tahap ini, yaitu pembuatan mekanik, elektronik, dan programming.

\section{Pembuatan mekanik}

Setelah gambaran garis besar bentuk robot dirancang, maka rangka dapat mulai dibuat. Umumnya rangka robot erbuat dari alumunium kotak atau alumunium siku. Satu ruas rangka terhubung satu sama lain dengan keling alumunium.

\section{Pembuatan sistem elektronika}

Bagian sistem elektronika dirancang sesuai dengan fungsi yang diinginkan. Misalnya untuk menggerakkan motor DC diperlukan h-brigde, sedangkan untuk menggerakkan relay diperlukan saklar transistor. Sensor-sensor yang akan digunakan dipelajari dan dipahami cara kerjanya. Pembuatan sistem elektronika ini meliputi tiga tahap:
- Design $\mathrm{PCB}$, misalnya dengan program proteus.

- Pencetakan PCB, bisa dengan Proboard.

- Perakitan dan pengujian rangkaian elektronika

\section{Pembuatan Software/Program}

Pembuatan software dilakukan setelah alat siap untuk diuji. Software ini ditanamkan (didownload) pada mikrokontroler sehingga alat peraga dapat berfungsi sesuai dengan yang diharapkan.

Tahap pembuatan program ini meliputi:

- Perancangan Algoritma atau alur program. Untuk fungsi yang sederhana, algoritma dapat dibuat langsung pada saat menulis program. Untuk fungsi yang kompleks, algoritma dibuat dengan menggunakan flow chart.

- Penulisan Program Penulisan program dalam Bahasa C.

- Compile dan download, yaitu mentransfer program yang kita tulis kepada ARDUINO UNO R3.

\section{Tahapan Uji coba}

Setelah kita mendownload program ke mikrokontroler ARDUINO R3 berarti kita siap melakukan tahapan terakhir dalam membuat alat peraga control motor DC, yaitu uji coba. Tahapan ini dengan menjalankan program agar bisa memutar arah motor.

\section{HASIL DAN PEMBAHASAN \\ Perancangan Hardware Blok Diagram}

Minimum System

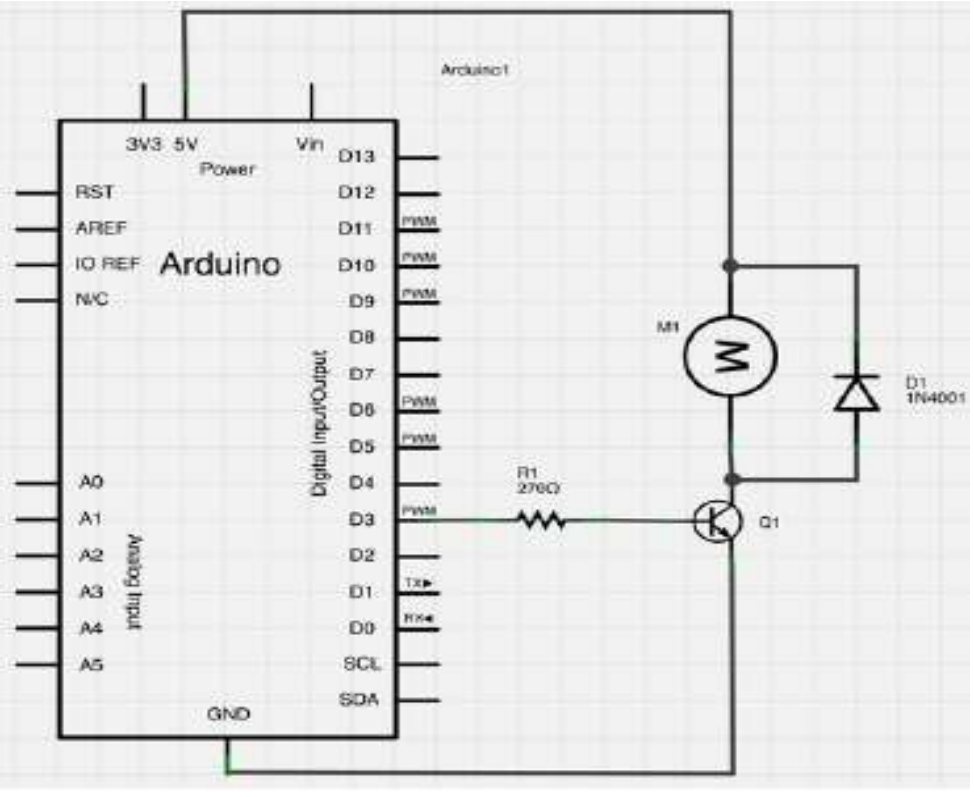


Gambar 2. ARDUINO R3

Suhariyanto / Trainer Pengendali Motor Dc Berbasis Mikrokontroler Arduino Dalam Pembelajaran Interface Dan Peripheral/JT,Vol 9 No.1, Maret 2017, pp 23 - 28

Catu Daya

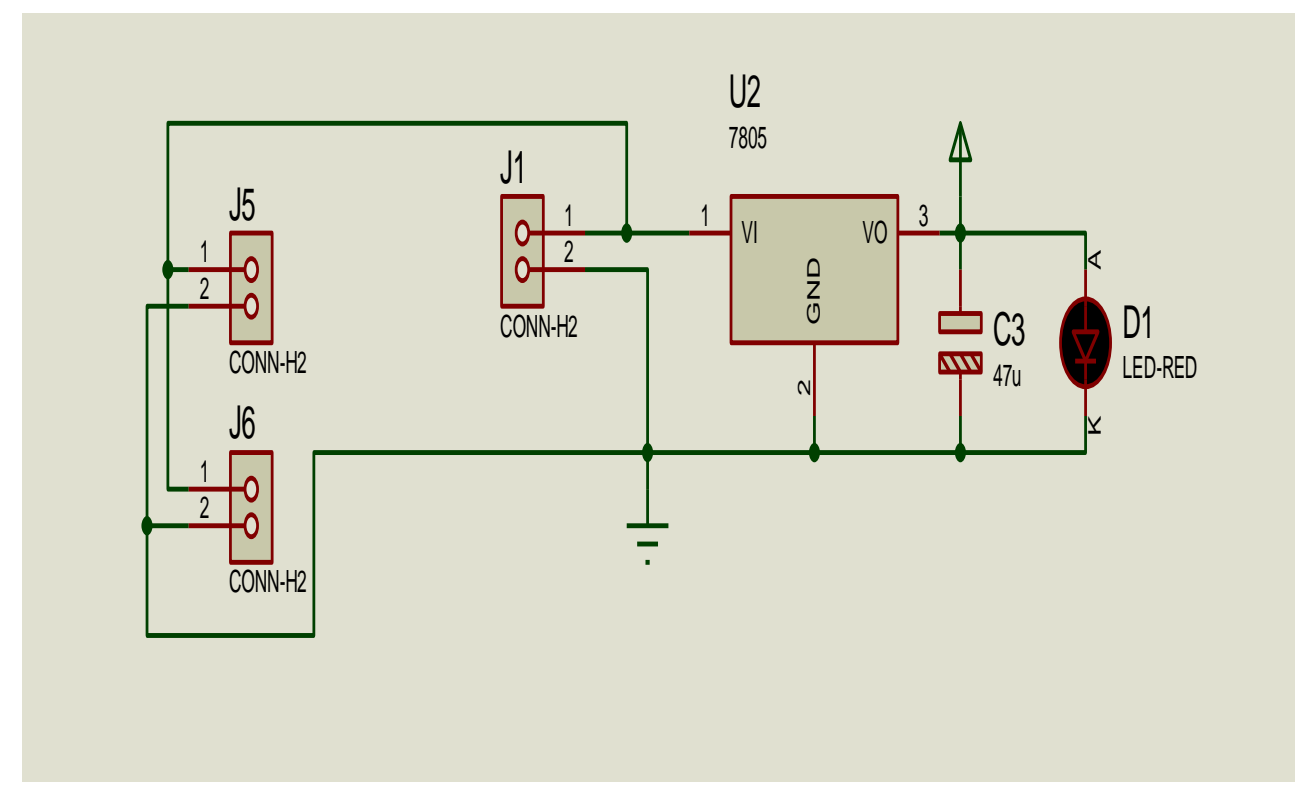

Gambar 3. Catu daya ARDUINO R3

\section{Desain Rangkaian Pengontrol Motor DC daan Cara Kerja}

Gambar desain rangkaian kontrol motor DC dapat dilihat pada gambar di bawah ini.

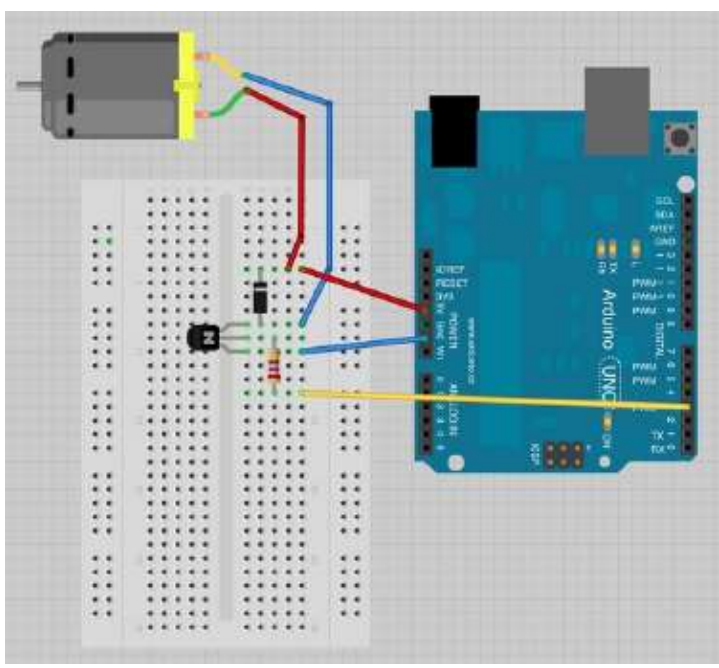

Gambar 4. Rangkaian Pengontrol Motor DC

Saat menyusun papan (breadboard), ada dua hal yang harus diperhatikani. Pertama, pastikan bahwa transistor adalah jalan yang benar. Sisi datar transistor harus berada di sisi kanan papan (breadbroad). Kedua ujung bergaris dari dioda harus menuju kabel power $+5 \mathrm{~V}$ - lihat gambarnya di atas!

Transistor bertindak seperti saklar, mengendalikan daya ke motor, Arduino pin 3 digunakan untuk matikan transistor dan diberi nama 'motorPin' di sketsa. Saat sketsa dimulai, ia meminta kita, untuk diingatkan bahwa untuk mengendalikan kecepatan motor perlu perlu memasukkan nilai antara 0 dan 255 di Serial Monitor.

\section{Perancangan Software}

Listing program :

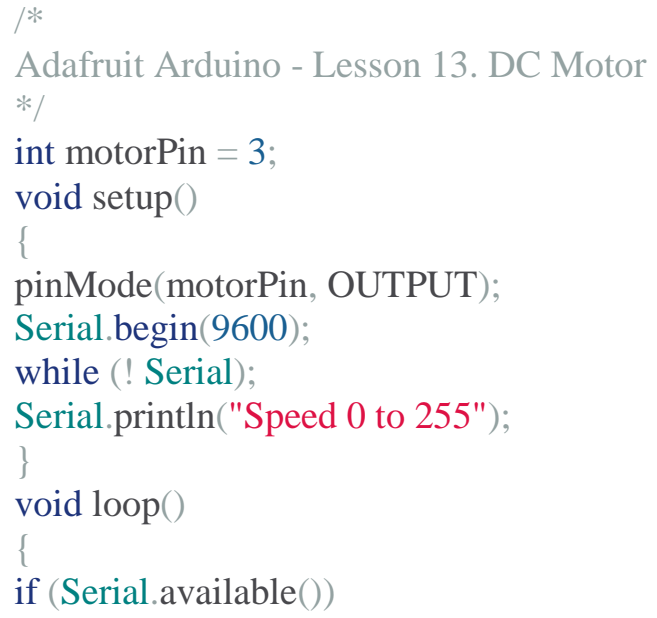


int speed $=$ Serial parseInt () ;

if ( speed $>=0 \& \&$ speed $<=255$ )

analogWrite(motorPin, speed);

Suhariyanto / Trainer Pengendali Motor Dc Berbasis Mikrokontroler Arduino Dalam Pembelajaran Interface Dan Peripheral/JT,Vol 9 No.1,

\section{Pengujian} Maret 2017, pp $23-28$

Transistor bertindak seperti saklar, mengendalikan daya ke motor, Arduino pin 3 digunakan untuk mematikan transistor dan matikan dan beri nama 'motorPin' di sketsa.

Saat sketsa dimulai, ia meminta Anda, untuk mengingatkan Anda bahwa untuk mengendalikan kecepatan motor. Setelah itu perlu memasukkan nilai antara 0 dan 255 di Serial Monitor.

Program pengujian :

int transistorPin $=9$; // dari digital pin 9 ke pin signal PWM kiri (menggerkkan motor) int transistorPin $2=11$; / dari digital pin 11 ke pin signal PWM kanan (menggerkkan motor) int relayPin $=7$; / dari digital pin 7 ke pin signal relay kiri (membalik putaran motor) int relayPin $2=5$; // dari digital pin 5 ke pin signal relay kanan (membalik putaran motor) void setup() \{

// set the transistor pin as an output pinMode(transistorPin, OUTPUT); pinMode(transistorPin2, OUTPUT); // set the relay pin as an output pinMode(relayPin, OUTPUT); pinMode(relayPin2, OUTPUT); \} void loop() \{ digitalWrite(7, LOW); // relay1 off - MAJU digitalWrite(5, LOW); // relay2 off - MAJU analogWrite $(9,255)$; // motor 1 on, full speed (nilai 0-255)

analogWrite(11, 255); // motor 2 on, full speed - (nilai 0-255)

delay(3000);

analogWrite $(9,0)$; // motor 1 off analogWrite $(11,0) ; / /$ motor 2 off delay(3000);

digitalWrite(7, HIGH); // relay1 on MUNDUR

digitalWrite(5, HIGH); // relay2 on -

MUNDUR analogWrite $(9,125)$; // motor 1 on, half speed - (nilai 0-255) analogWrite $(11,125)$; // motor 2 on, half speed - (nilai 0-255) $\operatorname{delay}(3000)$; analogWrite $(9,0)$; // motor 1 off analogWrite $(11,0)$; // motor 2 off delay(3000); \}

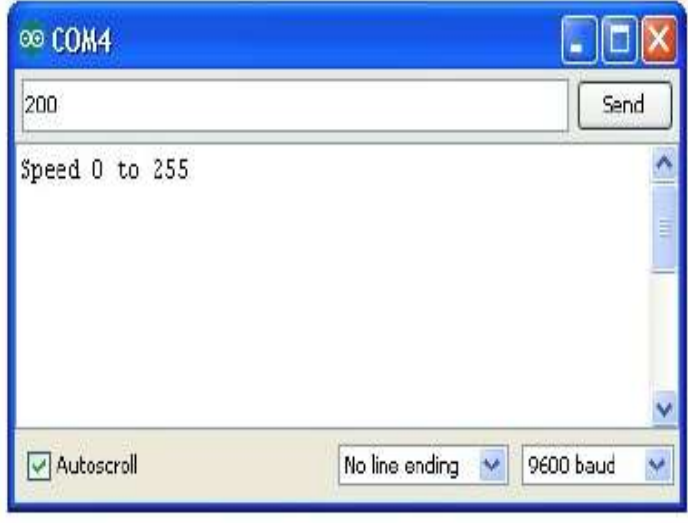

Gambar 5. Hasil Pengujian Motor

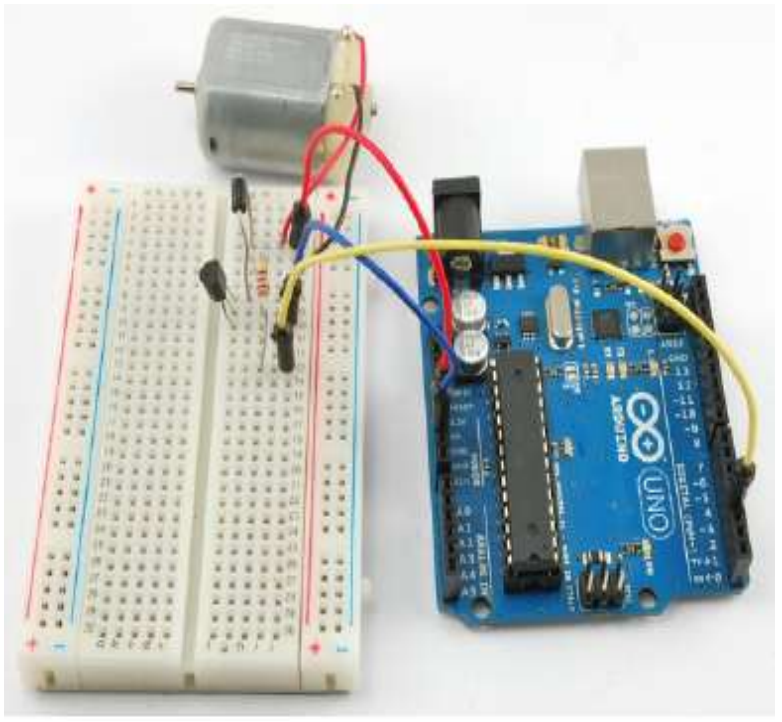

Gambar 6. Desain Alat Peraga Pengontrol Motor DC

\section{KESIMPULAN}

Dari hasil penelitian, dapat disimpulkan perputaran motor DC bisa lambat dan bisa cepat tergantung dari pengaturan program yang dibuat. Dari hasil pengujian menunjukkan arah perputaranbisa cepat atau lambat dengan memberikan pengaturan kecepatan 0 sampai 225.

\section{DAFTAR PUSTAKA}

A.Kadir, Panduan Praktis Mempelajari Aplikasi Mikrokontroler dan Pemograman 
Menggunakan Arduino, Yokyakarta: Penerbit Andi, 2013.
A. Kadir, Buku Pintar Pemograman Arduino, Yokyakarta: penerbit MediaKom, 2014.

Suhariyanto / Trainer Pengendali Motor Dc Berbasis Mikrokontroler Arduino Dalam Pembelajaran Interface Dan Peripheral/JT,Vol 9 No.1, Maret 2017, pp $23-28$

A.Kadir, Panduan Mempelajari Aneka Proyek Berbasis Mikrokontroler Arduino, Yokyakarta: Penerbit Andi, 2015.

M. Banzi, Getting started with Arduino. Sebastopol: O'Reilly Media,Inc. 2011

M. McRoberts, Beginning Arduino. New York: Apress, 2010.Arsyad, Azhar Prof. Dr. (2002). Media Pembelajaran. Jakarta: PT Raja Grafindo Persada
Sumad, 1972, di akses dari https://fairuzelsaid.wordpress.com/2011/05/ 24/pengertian-dan-tujuan-alat-peragapendidikan/tanggal 7 Juni 2017

Faizal, 2010, di akses dari https://fairuzelsaid.wordpress.com/2011/05/ 24/pengertian-dan-tujuan-alat-peragapendidikan/tanggal 7 Juni 2017 